\title{
MBAA Annual Conference Oral Presentation Abstracts
}

\section{Brewhouse Operations}

1. Using spectrophotometry to improve the brewing process of smaller craft breweries. $R$. Blankemeier, Stone Brewing Co., Escondido, CA

With more and more craft breweries opening, the quality and consistency of their beers comes into question. Establishing baseline specifications using simple analytical equipment is essential for maintaining brand and style consistency-even for small craft breweries with limited monetary resources. Establishing baseline specifications for core beer brands is important to carry quality and consistency throughout the growth of brewing capacity. The UV-Vis spectrophotometer is an essential tool to determine empirical specifications of beer and wort. The objective of this presentation is to introduce smaller craft breweries to the UV-Vis spectrophotometer, the cost of running assays, and the cost benefit of utilizing this essential piece of analytical equipment. In addition, this presentation will cover the specifics of bitterness, color, free amino nitrogen, vicinal diketones, oxidative precursors, betaglucans, and polyphenol assays and using those tests to help optimize the brewing process and diagnose issues. Included are studies that smaller craft breweries can use to determine the return on investment of purchasing and utilizing a UV-Vis spectrophotometer in their daily brewing process.

Rick Blankemeier left the world of natural gas process engineering for the realm of craft beer and hasn't looked back. Rick helped establish the standard operating procedures for $Q A$ and $Q C$ at Stone, as well as for the barrel and small-batch program. Rick has given presentations and seminars on quality assurance and spectrophotometry at Southern California MBAA technical meetings and the 2013 Craft Brewers Conference. Rick holds bachelor's and master's degrees in chemical engineering from the University of Colorado at Boulder. He currently works as the quality assurance analyst at Stone Brewing Co., specializing in small-batch and barrel-aged beer.

2. Some considerations on mash $\mathrm{pH}$ prediction. A. J. Delange, Mad Fox Brewing Company, Falls Church, VA

Clearly it would be advantageous if brewers could enter parameters describing their malts and water, the amounts of each, and the amounts of any salt, acid, or base additions into a spreadsheet or "app" and have it return a reliable mash $\mathrm{pH}$ prediction. This represents the holy grail for home brewers but would clearly be of value to craft and larger commercial brewers as well. In this presentation we offer a proton deficit/surfeit model in which the predicted $\mathrm{pH}$ is the $\mathrm{pH}$ at which the total of individual mash component proton deficits equals the total proton surfeit. We explore methods for determining (modeling) the proton surfeit/deficit for each relevant mash component. Among these are a Henderson-Hasselbalch-based model for carbonate and phosphate and, for malts, a simple (three term) Taylor series representation of their titration curves about the distilled water mash $\mathrm{pH}$. Some experimental data are given.

http://dx.doi.org/10.1094/TQ-50-3-0905-01

(c) 2013 Master Brewers Association of the Americas
While the models for many of the mash components may be sufficiently robust, this is not true for all of them. For example, calcium carbonate and lime additions do not deliver the alkalinity that stoichiometry predicts. A theoretical explanation as to why this may be so is presented. Larger difficulties may lie in obtaining data that accurately reflect the actual acidity or alkalinity of malts encountered in the brewhouse on a particular day. These are discussed, with emphasis on the laborious and time-consuming nature of properly done malt titrations. Variations between lab and brewhouse handling, between malt batches, and the fact that thermodynamic equilibrium is never reached in the mash tun are noted. We conclude that while accurate mash $\mathrm{pH}$ prediction may be feasible it may, depending on required accuracy, not be practical.

$A$. J. deLange is a retired electrical engineer with more than 40 years of experience in signal processing, $R F$ engineering, estimation, and analysis. He is also a home brewer with more than 25 years of experience who has particularly enjoyed applying the disciplines of his professional life to his hobby. He has a keen interest in brewing water chemistry and beer color analysis and has published and lectured on those subjects in the United States and abroad. He is a member of MBAA and $A S B C$. He has undergraduate and graduate degrees in electrical engineering from Cornell University and was employed by Zeta Associates in Fairfax, VA. He consults for Mad Fox Brewing Company in Falls Church, VA.

3. The influence of decoction mashing procedure on beer characteristics. Y. Ishizuka, T. Maruhashi, Y. Hida, and K. Oka, Suntory Liquors Limited, Osaka, Japan

Nitrogen compounds in mash contribute not only to beer taste and foam quality, but also affect the brewing process, provide the nitrogen source for yeast fermentation, and can affect beer filterability. Therefore, the control of protein modification during malting and mashing is very important, and we must consider optimizing the mashing procedures depending on malt quality, and vice versa. It has become popular to use malts with relatively high protein modification because they are both easy to use and economical. However, this may cause low fullness or an unpleasant aftertaste if the mashing method is not carefully considered. At the MBAA Annual Conference in 2010, we reported that decoction beer had better fullness and bitter quality than infusion beer when relatively low protein modified malt was used. At WBC 2012, we reported that the components of nitrogen compounds present in mash could also be controlled by the decoction mashing procedure (mashing-in temperature, rest temperature, or rate of temperature increase) and that, based on these results, it appears that high molecular weight nitrogen compounds are a good indicator of bitter quality and foam cling. As mentioned above, decoction mashing procedure influences beer characteristics when relatively low protein modified malt is used. Furthermore, the mashing procedure used after decoction may also change the degradation of nitrogen compounds and affect Maillard reaction products at the mash and wort boiling stage. In this study, we investigate the influences of mashing temperature, before and after the addition of decoction mash to residual mash, and 
discuss the effects of mashing procedure on beer characteristics, focusing on nitrogen compounds and Maillard reaction products that result from enzyme reactions during the mashing process.

Yusuke Ishizuka graduated with a master's degree in environmental studies from the University of Tokyo in 2011. After joining Suntory, he worked for two years in the Beer Development Department of Suntory Liquors Limited.

\section{Factors and new approaches for optimizing lautering operations. T. Audet, AB InBev, St. Louis, MO}

Use of lauter tuns for wort separation is an essential step in the recovery of extract converted in the mashing process. The factors affecting lautering are vast, and often only a few fundamental factors are considered. The presentation will first examine pre-lauter tun factors that can have a significant effect on extract efficiency. The presentation will then outline factors involved in the actual lautering process that affect extract efficiency. Finally, a review of innovative approaches to the operation of lauter tubs and resulting improvements in performance will be considered. For all parts of the presentation examples from Anheuser-Busch InBev lauter tun installations will be used.

Travis Audet has been brewing professionally since 1994 and has been a proud member of MBAA since 1997. He has worked in brew pubs, craft breweries, brewing research and development, and regional breweries in both Canada and the United States. Currently, Travis is a brewing specialist for Anheuser-Busch InBev (AB-I) based in St. Louis, MO. In his current role, he serves breweries in the AB-I North American zone, assisting in process improvement and optimization in all areas of brewing from raw materials to bright beer tanks. Travis has a degree in natural resources from the University of Maine, holds an Institute of Brewing and Distilling Diploma Brewer Certification, and is a current candidate for the Master Brewer Certification. In service to MBAA, Travis has held multiple voluntary roles, including district officer positions, Membership Committee chair, Board of Governors representative, and, currently, Education Committee chair.

\section{Packaging (Bottles, Draft and Cans)}

5. “One-way kegs": Helping brewers to increase sales volumes, while reducing environmental impact and production costs. A. D. Carter, Petainer Manufacturing USA Inc., Chicago, IL

A case study showing how a U.S. craft brewer brewing a German "alt" style draft beer is able to send product 3,000 miles for consumers to enjoy at 60 London (England) pubs. "One-way kegs" have allowed this customer to distribute a premium draft beer as a commercially viable global product. In addition to opening up new and distant markets, these kegs have also allowed this brewer to tackle important environmental challenges. The case study will illustrate benefits throughout the supply chain: saving fuel during transport, saving water stress, saving effluent charges, and saving energy. The commercial advantages are also illustrated. These include less capitol spent on packaging machinery, less equipment to maintain, and a smaller equipment footprint. Product quality and safety throughout the product cycle are discussed. This paper looks at the whole commercial and environmental impact. A lot of businesses claim to take environmental challenges seriously. One-way kegs can allow a brewing business to demonstrate use of a keg system that puts that into practice.
Andy Carter joined APV in 1984 and began a career as a supplier to the beer and beverage industries. Working up from manufacturing, through production control, service, and then sales, the rationalization of APV's kegging business in 1991 led to Andy being promoted to the position of sales and service manager with responsibility for sales of APV's keg-racking products around the world. Invensys acquired APV in 1997. Restructuring resulted in Andy's appointment as sales manager (brewing) for APV UK at Crawley. In this role he was responsible for all brewery process sales within the Unite Kingdom and for keg-racking products globally. The following year Andy was appointed as general manager of the keg division. In 2004, he joined KHS, where he was responsible for sales of packaging plants to the U.K. brewing and beverage industries. In 2011 Andy joined Petainer as a regional sales director, responsible for the U.K. and North American markets. The specialist PET engineering and technology business is pursuing business growth in new and existing markets with development of the unique Petainer keg and other large container systems. Andy has 29 years of experience in packaging projects for the beverage industry. A member of IBD, he has lectured, trained, and published extensively in Europe, the United States, and Asia Pacific regions.

6. A novel method for reduction of carbon dioxide consumption during can seaming process. Y. Tanaka, Kirin Brewery Company, Limited, Yokohama, Japan

While tackling individual environmental issues such as reducing $\mathrm{CO}_{2}$ emissions, Kirin has been constantly reminded that maintaining environmental sustainability, along the Kirin Group's value chain, has much to do with the continuity of society and of our business. Canned beer products were introduced into Japanese market in the 1970s. The can share has increased year by year, and these days it reaches around 70$80 \%$ of the market. As for Kirin Brewery production, $70 \%$ of the products are canned beer, and more than half of the $\mathrm{CO}_{2}$ consumption in the whole brewery is used for can production. We have developed technologies such as $\mathrm{CO}_{2}$ usage efficiency improvements in the can-filling process, but a further effort has been demanded to achieve the $\mathrm{CO}_{2}$ reduction target the Kirin Group is aiming for. Therefore we decided our next target area will be the seaming process. To prevent product oxidation, a huge volume of $\mathrm{CO}_{2}$ is purged to exclude $\mathrm{O}_{2}$ from the headspace of the liquid after beer filling and just before seaming, and this process has been controlled basically only through the $\mathrm{CO}_{2}$ flow rate. We successfully reduced $\mathrm{CO}_{2}$ usage by heating it in the supply line according to the combined gas law. As gas density is decreased by heating, the mass (weight) of $\mathrm{CO}_{2}$ could be reduced in the same gas flow volume as $\mathrm{CO}_{2}$ itself. $\mathrm{CO}_{2}$ temperature was controlled below the heat resistance of any parts of the supply line, thus we could construct this system only through the installment of a heating device. We also observed that headspace $\mathrm{O}_{2}$ became lower under high-temperature $\mathrm{CO}_{2}$ purging conditions. It is thought that headspace $\mathrm{O}_{2}$ also heated, and it seemed to be effective in reducing $\mathrm{O}_{2}$ density. None of the other concerns, such as odor, packaging duration, and seaming performance, were observed. This new method was able to reduce approximately $20 \% \mathrm{CO}_{2}$ usage in the can seaming process without any changes in beer quality and packaging performance.

After graduation from Ukiha technical high school in Fukuoka, Japan, Yasunori Tanaka joined Kirin Brewery and worked in the packaging area of the Fukuoka brewery from 1994 through 2009. He has developed his expertise especially in 
canning operations, including quality control, quality assurance, and efficient production. He was involved in the Fukuoka brewery renovation project in 2006. He moved to the Technical Development Department in 2009 and has been working on can material weight reduction and $\mathrm{CO}_{2}$ reduction in can fillers and seamers.

7. Keg manufacturing standards. M. S. Carpenter, Franke Beverage Systems, LaVergne, TN

Keg manufacturing standards in the United States (no documented standard), the United Kingdom (BFBi standard), and Germany (DIN standard) are discussed. This paper was written in response to dozens of inquiries regarding the internal pressure tolerance of stainless-steel kegs following the Red Hook incident. It explains what happens when a stainless-steel keg ruptures (including multiple photos), the safety features unique to the standard North American keg, and testing methods.

Mark Carpenter began working for Franke Beverage Systems in 2009. One of his first tasks at Franke was to develop keg service and repair capabilities, which allowed him to observe every conceivable keg failure mode and their respective results. In addition, as a part of Franke's Global Network Keg Services (GNKS), Mark regularly meets with other GNKS members from the United Kingdom, Germany, Czech Republic, and Poland to discuss keg repair techniques, failure modes, handling methods, and logistics.

8. Prevention of premature failure of polypropylene mat top belts in tunnel pasteurizers. J. L. Bland, ChemTreat, Glen Allen, VA

Polypropylene has been the material of choice for mat top conveyor belts in tunnel pasteurizers in recent years; however, premature catastrophic failure has cost the industry more than $\$ 50$ million in belt replacement costs alone over the past five years, not to mention lost production associated with downtime for belt replacement. These mat top conveyor belts, which are designed for 7-10 years of useful service life have experienced failure in as few as 3 years of in-service operation. This paper details the root cause analyses of a variety of premature belt failures and offers recommendations for maximizing the service life of polypropylene belts in tunnel pasteurizers in future operations.

Jack Bland has more than 35 years of experience in water treatment programs associated with more than 30 individual U.S. and Caribbean breweries. He has been an active MBAA member since 1980 and has published six MBAA technical papers and posters, two of which were granted the Outstanding Paper Award in packaging. Jack has also taught the Pasteurizer Treatment section for many years at the annual MBAA packaging course in Madison, WI. Jack retired from Chemtreat in 2012 and is a retained consultant to the company, focusing primarily on water treatment programs associated with the brewing industry. Jack is also current president of the Cooling Technology Institute, a global industry association headquartered in Houston, TX. Jack is proud to be a member of MBAA Districts Mid Atlantic and Caribbean.

\section{Sensory}

9. The effects of pH on beer haze, beer foam, and astringency perception. K. J. Siebert, Cornell University, Geneva, NY

Beer haze and foam and astringency perception are all strongly influenced by $\mathrm{pH}$. Beer haze formation is mainly due to interactions between barley hordein, a protein rich in proline, and polyphenols. Haze-active polyphenols bridge the protein molecules together, resulting in complexes; these can grow to become suspended insoluble particles, at which point they scatter light and result in turbidity. Astringency perception is also mainly due to precipitation of proline-rich proteins (normally present in saliva and providing lubrication of oral surfaces) by polyphenols. Proteins generally have the least solubility in water near their isoelectric points, where the net charge on the protein is 0 . Beer haze formation is greatest slightly above $\mathrm{pH} 4$ and is much weaker at both higher and lower pHs. However, the isoelectric point of barley hordein is considerably higher than 4 . The greatest precipitation of salivary proline-rich proteins by polyphenols also occurs slightly above $\mathrm{pH} 4$, and these proteins also have fairly high isoelectric points. So, it appears that the $\mathrm{pH}$ at which the strongest protein-polyphenol interaction occurs has something fundamental to do with the nature of the interaction between proline-rich proteins and polyphenols, rather than protein precipitation per se. Beer foam is well known to involve one or more barley albumen proteins forming complexes with iso-alpha-acids. Studies with both beer and a model system showed greater foam formation with higher $\mathrm{pH}$ within the beer range. The foam protein-iso-alpha-acid interaction mechanism appears not to be due to ionic bonding, and in fact, the net charge on the beer albumens associated with foam decreases with increasing $\mathrm{pH}$. Both the haze and foam interactions appear to result not from ionic bonding but from hydrogen or hydrophobic bonding or a combination of the two.

Karl Siebert received a Ph.D. degree in biochemistry from Penn State in 1970. He then joined the Stroh Brewery Company in Detroit, MI, where he spent 18 years and held positions from research associate to director of research. In 1990, Karl joined Cornell University as professor of biochemistry in the Department of Food Science and Technology. He served five years as department chair and now is involved in research, teaching, and extension. Karl is active as a consultant in beverage technology and chemometrics. He twice received MBAA Outstanding Paper Awards for papers he presented, and he and his colleague, Penny Lynn, received the ASBC Eric Kneen Memorial Award (for the best paper published in the Journal of the American Society of Brewing Chemists in the prior year) three times. Karl was named an honorary professor of the Moscow (Russia) State Academy of Food Processing in 1996, and in 1999 he received the ASBC Award of Distinction. He received the MBAA Award of Merit in 2011. He is currently a member of the ASBC Journal Editorial Board. Karl's research interests involve foam and haze in beverages, perception of astringency and other flavors, application of chemometric methods in food science, and assessment of microbiological risk.

10. Investigation for improving metallic flavor in thirdcategory beer. S. Yamamura, Suntory Liquors Limited, Ohragun, Gunma, Japan

"Metallic flavor" is a metal-like flavor that gives the impression of rusty iron or of a can. This flavor is easy to detect in beers with a light taste, such as third-category beers, and it is a factor that negatively impacts beer quality. Third-category beers have been rapidly expanding in the Japanese beer market, and the ratio of sales is about $35 \%$. Therefore, it is an urgent task for us to improve metallic flavor. Based on a previous study, it was known that the substances causing metallic 
flavor are 1,5-octadien-3-ol and its oxide 1,5-octadien-3-one, which are oxides from an unsaturated fatty acid derived from raw materials. Our attempts to reduce metallic flavor could not proceed, however, because we did not know how the substances are generated. We analyzed a product that was judged as having a strong metallic flavor in our sensory evaluation. It was confirmed that this product had a high iron concentration in the beer. Based on this fact, we performed an iron addition experiment to elucidate the mechanism generating the metallic flavor. From this, we developed the hypothesis that it is necessary to reduce the unsaturated fatty acid and iron concentrations in the beer to improve metallic flavor. We tried to reduce wort turbidity during the lautering process to decrease the unsaturated fatty acid, because it had already been reported that there is a correlation between wort turbidity and the concentration of the unsaturated fatty acid (Kühbeck et al., J. Inst. Brew. 112:222-231, 2006). We also tried to reduce the amount of kieselguhr to decrease the iron concentration, because kieselguhr includes some iron. As a result, we were able to reduce the substances causing the metallic flavor and to improve the sensory evaluation score dramatically. We also carried out a sensory evaluation after eating various foods and consuming beers with high and low iron concentrations. When there were high concentrations of iron, a metallic flavor could be detected in reaction to the unsaturated fatty acid derived from the food. From this result, we could prove our metallic flavor hypothesis.

Shinichiro Yamamura is an assistant brewmaster in the Suntory Tonegawa brewery. The main subject of his work is development of brewing technology. He majored in molecular biotechnology at Hiroshima University, and he was engaged in elucidation of molecular mechanisms of mouse olfactory. He joined Suntory Ltd. in 2010. He is now engaged in improving beer quality and development of brewing technology.

11. The perfect draught beer formula. J. Tippmann, T. Voß, H. Mann, and T. Becker, Technische Universität München - Lehrstuhl für Brau- und Getränketechnologie, Freising, Germany

The issue of draft beer is a very hot topic that is based on a lot of knowledge from trial and error and experience. For this reason, in recent years a series of studies was conducted in Weihenstephan, based on which has gradually arisen the formula for a perfect draft beer from a hygienic point of view. In the course of these investigations, various aspects of how to both build and maintain a dispensing system were examined, with hygienic handling always in the foreground. In the studies, which will be presented in this paper, physical and sensory parameters of draughted beer were examined more deeply. The first part of the presentation shows investigations on the selection of the correct beer tap. If this component is incorrectly selected, there will be heavy foaming and high $\mathrm{CO}_{2}$ losses, whereby the property of the beer is significantly altered. A series of trials was conducted to characterize the flow behavior of different beers at different flow rates with different temperatures in a variety of different beer glasses. The foaming was analyzed and evaluated scientifically. The second part of the presentation deals with the use of mixed gas (blends of $\mathrm{CO}_{2}$ and $\mathrm{N}_{2}$ ). Here, the focus of the investigation was mainly on sensory properties, but also on factors such as foam creation, stability, and consistency. After the implementation of a new analysis method, the $\mathrm{CO}_{2}$ and $\mathrm{N}_{2}$ contents in the tapped beers were analyzed. In addition, studies were performed to investigate the solving behavior of pre-assembled mixed gases.
Johannes Tippmann graduated from university in 2004 as a diploma engineer for brewing sciences and beverage technology. In 2005 he started his Ph.D. thesis with Prof. Sommer at the Lehrstuhl für Verfahrenstechnik disperser Systeme, TU München, on solid handling in the brewhouse. In 2012 he changed his affiliation and is now working as a group leader for the "brewhouse processing and dispense systems" work group at the Lehrstuhl für Brau- und Getränketechnologie, TU München. Since 2000 he has worked as a student research assistant in dispensing systems and collected lots of experiences in this subject area. Since 2006, he has been responsible for research issues in dispense systems. He is also a member of the "dispensing systems" technical committees of the government association for food and catering industry (BGN) and of the DIN German Institute for Standardization.

12. Critical review of different sensory methods. M. Zarnkow, Technische Universität München, Freising, Germany

This project covers the following areas: sensory analysis of beer and statistical evaluation of sensory test results. The aim was to develop a model that is appropriate to compare different sensory methodologies. The model is based on a modified ranking method. Within this work, three panels performed three difference tests. The stimuli in each test consisted of pale lager with different amounts of diacetyl. First the panel judges had to check the homogeneity for sensory materials. This test combines a ranking test according to ISO 8587:2006 with an intensity measurement. Afterward the panels carried out triangle tests according to ISO 4120:2004 and paired comparison tests according to ISO 5495:2007. It could be shown that a paired comparison test is more sensitive than a triangle test. The ranking test seemed to be the most difficult test in the case of finding differences between samples. Initial weights and distributions of samples can be computed with the model, and the boundary of two different samples can be defined. In these, judges should be able to discriminate them. The model can also be used to control a sample production for sensory analysis. The function of the model was proofed and validated. It can be used for each sample material. In addition an assumption was made to describe the difficulty of difference tests. In this way a comparison of tests is possible.

Martin Zarnkow apprenticed as a brewer and maltster from 1989 to 1991 at a small brewery in Frankonia. Martin graduated with a Dipl.-Ing. (FH) degree, with brewing technology option, in 1996 from TU München Weihenstephan. Martin then worked as a brewmaster for one year in a medium-sized brewery in Germany. Since 1997 he has been the head of the research group for beer and beverage technologies at the Lehrstuhl für Brau- und Getränketechnologie (institute for beer and beverage technology) at TU München in Weihenstephan. In 2010 his finished his external Ph.D. research at the University College of Cork, Ireland, on the subject "Proso Millet (Panicum miliaceum L.): A Sustainable Raw Material for the Malting and Brewing Process."

\section{Food Safety}

13. Validation concepts for foam cleaning systems in the brewery. R. Folz, Versuchs- und Lehranstalt für Brauerei in Berlin (VLB), Berlin, Germany

Long-term studies to investigate the performance and effectiveness of foam cleaning and disinfection in brewing and 
packaging operations by VLB together with the industry has led to a further control point definition to create a microbiological firewall on-line in the process. Trials performed in pilot scale as well as in industrial applications led to two developments to better classify, control, and document results during foam application. CIP and COP procedures are compared, especially in the crucial process of outer filler cleaning. Foam classes are defined that build the background for an apparative set-up, which releases an optical signal to classify the foam based on cluster analysis before being applied. Further developments alternate the foam chemistry itself to combine the goal of cleaning directly with an indicator that visually validates the effect regarding organic residues based on a permanganate reaction by a color change. During these developments, existing retention test media were compared and led to a new standard staining method in order to describe the sensitivity of the methods. Through the synergy of the new validation developments the author will create a holistic view of the application of foam cleaning in the brewing industry in order to enhance quality transformation goals by on-line validation results.

In his executive function as head of the VLB Department of Brewing \& Beverage Science and Applications (BBSA), Roland Folz is involved in driving forward the process of VLB's internationalization. VLB is a German independent research institute and service provider for the brewing and beverage industries. Roland has built up his brewing career from scratch, starting with his technical apprenticeship as a brewer and maltster at the Beck's brewery up to his doctorate degree with a thesis on flavor stability and PET topics. In between he has been technical director for the Preussen Pils brewery and plant manager for the Oettinger Group. Under Roland's leadership the BBSA at VLB-Berlin has become to an international provider of mission-orientated research and solutions regarding technological topics, global consultancies, and international training courses. With his team of experienced engineers, Roland is working on sustainable developments for the brewing industry, future brewing streams, and fermentation and applied microbiological concepts and control mechanisms. Roland is active on the Board of Examiners of IBD (Institute of Brewing and Distilling) and is heading the Working Group for Inline Measurement Techniques of MEBAK (Middle European Brewing Analysis Committee). Furthermore, he is a member of ISBT (International Society of Beverage Technologists), MBAA, and $A S B C$.

14. Monitoring the cleaning and sterilization of kegs. C. Nimptsch, Profamo Inc., Rancho Palos Verdes, CA

The cleaning and sterilization of kegs is a critical component of any brewery's microbiological QA and program. However, automated keg lines are black boxes for most brewers, and pulling microsamples is a long and complicated process with many opportunities for false results. As such, it is very important to be able to monitor the keg line's cleaning and sterilization efficiency with a simple and accurate monitor. Electronic test kegs afford the user a way of monitoring these processes. Data collected from an electronic test keg on various keg lines will be analyzed. Solutions to common problems will be discussed, as will best practices. A focus will be placed on the importance of high-pressure saturated steam to ensure sterilization of kegs.

Chris Nimptsch, president of Profamo Inc., has been a member of both MBAA and ASBC since 1994. He made presenta- tions on keg line operations at the 2008 World Brewing Congress and the 2013 Craft Brewers Conference. Chris has a B.S. degree from McGill University in Montreal, Canada; a law degree from the University of Ottawa in Ottawa, Canada; and is a graduate of the Siebel Institute of Technology. After practicing law for seven long, boring years, Chris finally came to his senses and started working in the brewing industry (his true love) when he joined the family business in 1994. Profamo Inc., has been a supplier of QA and process control equipment to the brewing industry since 1976 and now represents 12 manufacturers from all over the world.

15. The importance of supplier quality and its impact on brewing operations. B. A. Rush, The Samuel Adams Brewing Company, Cincinnati, $\mathrm{OH}$

In today's business environment, supplier quality is a basic requirement needed to deliver a superior product to your consumers. The business models designed around price of materials, on-time delivery, and lack of defects won't get you very far in today's food production environments. With the recent passing of the Food Safety Modernization Act (FSMA), today's business focus needs to be around food safety and the pre-requisite programs required to be a world-class supplier in the food and beverage industries. This presentation will provide information on the basics of assessing a supplier for overall risk to the business through risk assessment and auditing. The result of the risk assessment will help to determine the higher risk suppliers to your business and at what frequency the customer may want to review or audit suppliers for risks or gaps in their business. An audit of your supplier should not be limited to food safety, as it will also need to focus on how the supplier manages consumer complaints, communication with employees, managing change, and the effectiveness of training, to name a few. More and more of the supplier audits today look at all aspects of the supplier's ability to be a consistent source of the highest quality materials that the brewery can use to deliver a quality product to the end consumer. The audit of a supplier today covers many areas of the business, and it must paint a clear picture as to what challenges and opportunities a supplier may have that can potentially impact the customer in any way. The focus of supplier quality for the Boston Beer Company has always been a top priority, but as we grow, we are seeing that it is a critical piece in the business model that our founder has built this business on.

Brad Rush, manager of supplier quality, joined The Samuel Adams Brewing Company in 2007. Brad holds a B.S. degree in environmental analysis from Carroll College in Waukesha, WI, and certificate in quality engineering from the Milwaukee School of Engineering; six sigma green belt certification from Lakeshore Technical College; and a diploma in advanced management and leadership from The University of Wisconsin-Madison, School of Business. Brad also has studied with the American Brewers Guild and Institute of Brewing. Brad joined the Boston Beer Company as the quality manager for the Cincinnati brewery and managed the packaging and analytical quality groups. In his current role he is in charge of the supplier quality program for Boston Beer and supports comanufacture operations throughout North America. His previous experience includes a strong background in brewing, research, and operations at Jacob Leinenkugel Brewing Company and Miller Brewing Company, as well as hands-on quality analysis with an emphasis in sensory evaluation and quality. 
16. Yes, beer is good, but is it safe? A review of foodborne pathogen and toxic substance levels in beer. A. K. Hamm and M. Bunning, Colorado State University Department of Food Science, Fort Collins, CO

Beer is a widely consumed food product, and brewers should be aware of emerging safety issues concerning foodborne microorganisms and toxic substances. Historically, beer consumption was encouraged in areas where drinking water was contaminated with pathogens. The malting and brewing process includes several "hurdles" for pathogens or potentially dangerous chemicals they must survive. The ethanol content, low $\mathrm{pH}$, lack of nutrients, hop acids and anti-microbial properties, and high $\mathrm{CO}_{2}$ and low $\mathrm{O}_{2}$ levels in finished beer serve as obstacles for potentially dangerous microbes and chemicals. However, questionable levels of toxic substances such as aflatoxins, nitrosamines, pesticides, and heavy metals have been found in beers, especially those brewed in developing countries. Even low amounts of toxins may pose a threat due to chronic exposure. Current research evidence indicates beer is a safe beverage when consumed in moderate amounts. Foodborne pathogens cannot survive in beer at appreciable amounts, and potentially toxic chemicals do not generally occur at harmful levels. As a take-home message, the most dangerous element in beer produced in the United States is ethanol. The potential benefits of beer consumption with food contaminated with a pathogen will also be discussed.

Ali Hamm has been an MBAA Rocky Mountain District member since 2007 and has attended the MBAA Brewing and Malting Science course in Madison, WI. For the past seven years Ali has worked in several areas of the hops industry, including research, consulting, and sales. She has given several presentations at local brewing conferences and workshops, including the local MBAA district. Ali obtained a bachelor's degree in molecular and cell biology from UC Berkeley and then moved on to Colorado State University for a master's degree in horticulture. She is currently in the food sciences doctorate program at Colorado State University and is helping to develop a new fermentation microbiology course.

\section{Sustainability}

17. New materials for upgrading biogas to renewable natural gas. S. M. Wilson, M. A. Petruska, J. D. Carruthers, E. A. Sturm, and N. E. Megonnell, ATMI, Danbury, CT, and A. Primmer, MV LLC, Golden, CO

Typical commercial brewing processes consume vast amounts of water for the production of beer and spirits. As regulations around disposal and treatment of wastewater become more stringent and energy costs continue to rise, there is a need for small and large breweries alike to examine the entire lifecycle of the raw materials used in their manufacturing processes. One area that has the potential to both reduce strain on municipal water treatment plants and provide an additional revenue stream for breweries is the anaerobic digestion of process wastewater and surplus yeast to produce biogas. The composition of this biogas is primarily methane $\left(\mathrm{CH}_{4}\right)$ and carbon dioxide $\left(\mathrm{CO}_{2}\right)$, with other components present depending upon the specific source. In order to utilize biogas as a replacement for natural gas, it typically must be upgraded to $0-3 \% \mathrm{CO}_{2}$ with specific restrictions and requirements dependent upon utility company guidelines and local regulations. To this end, ATMI has developed BrightBlack carbon, a molecular sieve material based on polyvinylidene chloride (PVDC), which has the ability to selectively capture $\mathrm{CO}_{2}$ from a biogas stream with minimal sacrifice to overall $\mathrm{CH}_{4}$ production. ATMI and MV LLC have field tested a mobile pilot-scale vacuum swing adsorption (VSA) system at a commercial beverage manufacturer and two municipal wastewater treatment plants in the United States. The product gas produced during these field trials was found to meet pipeline and/or vehicle fuel purity requirements for $\mathrm{CO}_{2}$, while maintaining $\mathrm{CH}_{4}$ product yields of $\geq 85 \%$. The results of this field testing and the BrightBlack adsorbent characteristics will be discussed.

Neal Megonnell is director of platform marketing for ATMI. He holds a bachelor's degree in chemistry from the University of Pittsburgh and a master's degree in chemical engineering and colloids, polymers, and surfaces from Carnegie Mellon University. He has over 20 years of experience in the activated carbon industry, has published many articles in various trade journals and industry publications, and holds two patents related to activated carbon. He is currently a member of the ASTM D-28 Activated Carbon Committee, as well as the American Water Works Association B604 Activated Carbon Committee. He can be reached by telephone at +1.203.241. 4511 or e-mail at nmegonnell@atmi.com.

\section{Practical sustainability projects for breweries.} M. Bailey, Odell Brewing Co., Fort Collins, CO

Brewers feel close to the environment and are aware of the impact brewing beer has on the environment. Often, for small and large breweries, finding sustainability projects that have a significant environmental impact on operations are difficult to put into action. Common hurdles include capital, time, experience, and resources. This presentation will cover projects from Odell Brewing that can be implemented with little capital and time. The discussion will provide theory, plans, hurdles, and results of projects. Odell Brewing will cover its "closed-loop" bottle line vacuum pump and "zero-landfill" projects. The closed-loop vacuum pump project converted an open-loop vacuum pump to a closed-loop pump that reuses water many times, only needing to top off water to compensate for slight evaporation. A common problem with the closed-loop system is the temperature of reused water. Cooling of reused water is accomplished using an incoming city water and heat exchanger that is then used for two additional purposes after cooling. Implementation of the vacuum pump project reduced water in the brewery $14 \%$, equivalent to $1,321,000$ gal saved in 2012. Also covered will be efforts to overcome hurdles, habits, and implementation of a zero-landfill program at a brewery.

Matt Bailey is the maintenance, engineering manager, and sustainability coordinator at Odell Brewing. He oversees all things regarding maintaining and installing new production equipment, facility upkeep, and grounds at Odell Brewing. He attended Old Dominion University in Norfolk, VA, and Colorado State University in Fort Collins, CO, to acquire a B.S. degree in electrical engineering. While in college, he picked up home brewing as a hobby, which helped fuel his passion for beer, before joining the brewery workforce. Prior to joining Odell Brewing in 2010, he worked at Anheuser-Busch in Fort Collins, working in several different areas, including instrumentation, packaging process improvement, and maintenance reliability, and as a project engineer.

19. The algebra of sustainability: Technical metrics for the brewery. J. Jurado, Susquehanna Brewing Co., Pittston, PA

An infrequently tested proposition from economics is that competitive pressure will force breweries to be efficient. Key ratios and sustainable development indicators (SDI) help focus 
an approach to sustainability into real and quantifiable action. An attempt to create an aggregate measure of various aspects of sustainability suggests a profile of indices that provide a technical perspective that is global, like world-class manufacturing, but with transparent numerical quantification. By excluding social factors, often a key part of sustainability considerations (i.e., community involvement), the role of the brewer in candidly calculating and presenting SDIs is made easier and clear. Key ratios such as $\mathrm{MJ} / \mathrm{hL}$, g of $\mathrm{CO}_{2} / \mathrm{L}$, or hL of water/hL of finished beer help the brewery understand basic primary resource drivers of the enterprise and, if metered sufficiently, of the underlying unit operations within the enterprise. A family of key ratios comprise a new aggregate SDI, which is framed on simple math that demystifies the novel metric, and in which specific sustainable developments at breweries can be seen to influence the SDI. The desired result is that competitive pressure in reducing SDI will motivate breweries to commit to more-sustainable investments in their production operations. Independent craft breweries have supported this development work with travel grants for the presenter to obtain order-of-magnitude scaling data.

Jaime Jurado served as MBAA President in 2005 following service as the editorial board chair of the Technical Quarterly. With an undergraduate chemical engineering degree, Jaime's brewing career commenced formally after he completed a brewing apprenticeship in the Bavarian breweries of Patrizier-Bräu AG in 1983. Jaime spent 1984 and 1985 working as a project engineer in the London brewery of Truman, Hanbury \& Buxton and at the Smithwick brewery in Ireland. He was hired as an assistant brewmaster at The Lion Brewery in Wilkes-Barre (the company which would fund his M.S. degree in electrical engineering). Jaime advanced to the role of master brewer at the brewery and then moved on to a management opportunity at Courage Brewing Ltd. After two years, he reduced his employment to part-time to study and perform research in the Department of Engineering Science at Oxford University, where his research resulted in several publications. He was recruited by Stroh for a new brewery in Rajasthan, India, and other projects. He departed Stroh to become the director of brewing operations at The Gambrinus Company breweries, where he stayed for nearly 15 years. He completed an 18 month "working sabbatical" to design, procure, and commission a new small regional brewery using novel technologies aligned with sustainable explorations across the enterprise. He also provided engineering support for the Dingle Distillery in Ireland. Jaime currently is doing engineering consulting work and planning for a new adventure.

\section{World Class Management}

20. U.S. beer industry insights. L. Jones, Beer Institute, Washington, DC

The U.S. beer industry is in the midst of significant demographic and economic changes. The combined impacts of the 2008 recession and the coming-of-age of the millennial generation have clearly left their mark on the U.S. beer business. Despite these setbacks, the beer industry has adapted to a new marketplace and set a new course. The Beer Institute and its predecessor organization, the USBA, have been tracking the beer industry since the 1940s and have gathered detailed data and insights that help explain where we have been and where we may go from here.
Lester Jones serves as chief economist and senior director of research services for the Beer Institute. In this capacity, he serves as the primary researcher and economist on issues affecting brewers and importers of more than $90 \%$ of the beer consumed in the United States. He is responsible for the biennial "Beer Serves America" study showing the total contribution of the beer industry to America's economy through the impact of jobs, wages, and taxes, from the national level to individual state legislative districts. He is also a regular presenter at industry events around the country and comments on industry trends in consumption, taxation, and economic policy. Lester joined the Beer Institute in 2004 and brings 20 years of business and economic research experience to the beer industry's national trade association. Prior to joining the Beer Institute, Lester was with Arbitron, Inc., an international media and marketing research firm. At Arbitron, he managed consumer research studies. Prior to Arbitron, he was assistant director of the Regional Economics Studies Institute at Towson State University. Lester received his M.S. degree in economics from the University of Delaware, where he specialized in regional economics and forecasting. He obtained his B.A. degree in economics from the University of Maryland Baltimore County.

21. The $20 \%$ solution for consistent beer quality. A. T. Pringle, Pringle-Scott LLC, St. Louis, MO

Producing a beer with consistent sensory and analytical attributes is an important aspect of quality. For a new brewery this can be a daunting task as there are a seemingly endless number of items in the literature to measure and control. The Pareto principle states that $80 \%$ of the effects come from $20 \%$ of the causes. Therefore, to make efficient use of their resources brewers should identify and control those vital few $(20 \%)$ causes that result in the majority of the inconsistency. One approach is to view the brewing process as a series of inputs, processes, and outputs. Through this approach product consistency can be achieved by controlling the inputs and a few key factors in each of the brewery processes. Control of the primary inputs to the overall process can be achieved by accepting shipments based on certificates of analysis, sensory analysis, and periodically auditing critical parameters. In the case of individual brewery processes (brewhouse, fermentation, conditioning, and finishing), each can be controlled by identifying and controlling a few factors that have a major effect on the important attributes of finished beer. Because each process is separate, but interdependent, it is critical to measure the outputs from individual processes. Fermentability, free amino nitrogen, and bitterness are examples of wort parameters that could be measured, as well as gravity, since these parameters affect the performance of the next process (fermentation) and the finished beer. The outputs of the entire process are the analytical and sensory attributes of the packaged beer, where the ultimate test of consistency is their trueness-to-type.

Alastair Pringle earned undergraduate and graduate degrees in microbiology. He joined Anheuser-Busch in 1984 following five years of postdoctoral research. At AnheuserBusch Alastair held a number of technical management positions, including director of brewing research, where his responsibilities included all aspects of the brewing process. He is currently the principal consultant at Pringle-Scott LLC, a science-based consulting company that works with craft breweries on process control and quality. In addition, Alastair teaches microbiology at Maryville University in St. Louis, MO, and is a member of the IBD Board of Examiners. 
22. The use of Kaizens as a method for continuous improvement in a unionized 108 year old regional brewery: Framework and real results from The Lion Brewery, Wilkes-Barre, PA. L. Orlandi, The Lion Brewery Inc., Wilkes Barre, PA

Kaizen process improvement and problem abatement strategy that is in place in one of the most traditional unionized breweries around is discussed. The Lion Brewery will share its story of the successful implementation of Kaizen lean manufacturing principles.

Leo Orlandini is currently the master brewer and director of operations at The Lion Brewery, where he has 25 years of brewing management experience. The Lion Brewery is a 108 year old regional brewery located in Wilkes-Barre, PA. Leo received his B.S. degree in biology from Wilkes College in 1983 and began his career with The Lion in 1988 as a quality assurance technician. He was promoted to quality assurance manager in 1990. He attended the Siebel Institute of Technology in 1991 and received his diploma in brewing sciences. In 1999, Leo was named the inaugural Mid-Size Brewmaster of the Year at the Great American Beer Festival.

\section{Utilities Management}

23. VeSave solution to reuse wastewater as technical water and save a significant amount of money. J. S. Krogh, DWE A/S, Vejle, Denmark

Water/wastewater utilization with VeSave solutions concept is discussed. Saving of water by using wastewater as technical water. Wastewater without any vira, bacteria, or suspended solids to be used as technical water in various areas of the brewery to optimize potable water usage consumption, as well as reduce utility costs. Test case done on a 4 million hL brewery that saved US\$3 million per year with a capital expenditure investment of US $\$ 1.5$ million, giving a simple pay back on investment in 6-8 months. Based on optimization of water balance in a brewery, it was identified where to use recovered clean wastewater as technical water and, thereby, save the cost for usage of water, as well as the cost for treatment and discharge of wastewater.

J. S. Krogh is CEO and founder of companies specializing in energy saving and value engineering.

24. Breaking the barriers to collaborative waste-to-energy systems. J. C. Vanvoorhis, Symbiont Science, Engineering and Construction, Inc., Milwaukee, WI

The number of breweries in the United States is at the highest level since prohibition ended in 1933. Craft brewing is the fastest growing market segment of the U.S. alcoholic beverage industry, according to data gathered by the Brewers Association. Annually, breweries in the United States spend over \$200 million on energy. Total energy expenditures for malt beverages account for $56 \%$ of expenditures. Energy consumption is equal to $3-8 \%$ of the production costs of beer, making energy efficiency improvement an important way to reduce costs, especially in times of high energy price volatility. Uncertain energy prices in today's marketplace negatively affect predictable earnings, a concern for companies in the beer industry. For public and private companies alike, increasing energy prices are driving up costs and decreasing their value added. Successful, cost-effective investment into energy efficiency technologies such as waste-to-energy meets the challenge of maintaining the output of a high-quality product. Energy efficiency is an important component of a company's environmen- tal strategy, as well. End-of-pipe solutions can be expensive and inefficient, while energy efficiency can often be an inexpensive opportunity to reduce pollutant emissions. Energy efficiency can be an effective strategy to work toward the "triple bottom line" that focuses on the social, economic, and environmental aspects of a business. Waste-to-energy is a costeffective way to reduce energy consumption within a short payback period and accrue other benefits, such as reducing carbon dioxide emissions, reducing waste, and saving water. Creating energy from waste materials of the brewing process is important for breweries that are concerned with changing regulations. Today and in the future it will become very difficult for the brewing industry to dispose of its waste materials. Due to new regulations and higher standards for waste treatment, producers are being forced to find new methods of costneutral discharge of their biological waste that also meet regulatory requirements. This presentation will examine energy efficiency opportunities available to breweries using waste-toenergy technologies and financing to implement projects that result in an aggressive payback. We will explore anaerobic wastewater treatment, an alternative method for treating industrial wastewater that converts organic compounds in the wastewater into a renewable biogas that can be used to create energy on site. We will also explore several breweries that are using this technology and the positive return on investment. If return on investment is the primary barrier to realizing all the benefits of waste-to-energy projects, then one must consider the financial benefit of tax credits associated with energy recovery, as such credits will have a significant impact on project payback. We will explore financial aspects of these projects, including cumulative incentives, grants, loans, tax credits, and private equity. Mezzanine and traditional financing, other loan programs, negotiated incentives, and tax credit programs will also be discussed.

Jeff VanVoorhis has been a member of MBAA for more than five years and has contributed to the organization as a presenter on various brewing technology topics. Jeff is a senior project manager at Symbiont, who, since 1995, has specialized in industrial wastewater treatment, waste minimization, and renewable energy. Jeff holds a bachelor's degree in civil engineering from Purdue University and an MBA from Marquette University. Jeff has served as a project manager on numerous industrial wastewater projects that have total construction costs exceeding $\$ 100$ million. During the past year, Jeff has been integrally involved in the design of wastewater energy production and recovery for two regional waste-to-energy designs in the state of Wisconsin, which produce 2 and $3.2 \mathrm{MW}$ of green electric energy. He also has served as lead design engineer on comprehensive studies for energy use at digestion facilities for numerous industrial wastewater plants.

25. Case study-Executing a $210 \mathrm{~kW}$ combined heat and power project. M. A. Linsberg, Enerfab, Cincinnati, $\mathrm{OH}$

Combined heat and power (CHP) is an efficient and clean approach to generating electricity and useful thermal energy from a single source of fuel. CHP has been in use in the Unites States for more than 100 years and currently represents approximately $8 \%$ of all generating capacity or $82,000 \mathrm{MW}$, located at over 3,600 industrial and commercial facilities. Centralized electric power generation in the United States typically converts $34-35 \%$ of the fuel consumed into electricity, with the remainder of the energy lost in the form of waste heat. Installing a CHP system that uses thermal energy and electricity can result in $60-85 \%$ of the fuel energy being utilized. 
Breweries are great potential candidates for implementing CHP because electricity, steam, and hot water are all requirements of the brewing and packaging processes. Although there are several U.S. breweries that have installed CHP systems, the majority have not. We believe there is great opportunity for additional U.S. breweries to cost effectively implement CHP projects. Successful execution of a CHP project requires financial, legal, engineering, construction, and environmental expertise. The case study presented describes the process of developing a $210 \mathrm{~kW} \mathrm{CHP} \mathrm{project} \mathrm{from} \mathrm{concept} \mathrm{though} \mathrm{start-up.}$ The steps described in the study are applicable to most CHP projects no matter the size.

Mark Linsberg is the director of alternative energy at Enerfab, where he has worked for three years. Mark has 30 years of experience in the energy industry. Prior to joining Enerfab, he worked for Dayton Power and Light, East Kentucky Power Cooperative, and Dravo in a variety of engineering and management positions. Mark is a licensed professional engineer in Ohio and received his undergraduate degree in construction engineering from Purdue University.

\section{Yeast, Fermentation, and Microbiology}

26. Yeast mitochondria-Their influence on brewer's yeast fermentation and medical research. G. G. Stewart, GGStewart Associates, Cardiff, U.K.

Brewer's yeast strains (both lager and ale cultures) belong to a commercially significant grouping of yeast species that are used for the production of food, alcoholic beverages, and drugs for medicinal purposes. In addition, this yeast group is an invaluable model eukaryote because it is a single cell that can be genetically manipulated and cultured in the laboratory. The fact that it possesses a cell structure similar to plants and animals, including humans, that includes cell walls, a nucleus, vacuole(s), membranes, and mitochondria is also very important. In Saccharomyces cerevisiae and related species (including brewer's yeast strains) the most frequent spontaneous mutation is to the specific DNA contained in its mitochondria (mtDNA). This mutation is termed respiratory deficiency (RD) or petite because of the small size of the resulting colonies compared with the respiratory sufficient variant. The phenotypic effects of the RD mutation in a brewer's yeast culture are profound, and examples, particularly during wort fermentation, will be discussed. In addition, fundamental research on yeast mtDNA has assisted our knowledge of human mitochondrial function and disease. There is a group of diseases caused by dysfunctional mtDNA often as a result of mutation of mtDNA. These diseases include type one diabetes, deafness, hereditary optic neuropathy, and epilepsy, to name just a few. Mitochondrial research with yeast has provided considerable information and assisted medical research on many of the diseases listed above. Indeed, current research removing the mtDNA from the ovaries of a diseased patient and replacing it with unmutated mtDNA from a donor to produce healthy zygotes is a novel technique with significant potential. Importantly, in the context of this presentation, without mitochondrial research on brewer's yeast and its close relatives, these medical developments would have been inhibited, impeded, and protracted.

Graham Stewart, emeritus professor in brewing and distilling at Heriot-Watt University, Edinburgh, Scotland, was director and professor of the International Centre for Brewing and Distilling, Heriot-Watt University, from 1994 to 2007. He received his BS. (Honors) degree in microbiology and bio- chemistry from the University of Wales, Cardiff, and Ph.D. and D.S. degrees from Bath University. He was a lecturer in biochemistry in the School of Pharmacy at Portsmouth College of Technology (now Portsmouth University) from 1967 to 1969. From 1969 to 1994 he held a number of technical positions with Labatt's in Canada and from 1986 to 1994 was its brewing technical director. He was president of the Institute of Brewing (now the Institute of Brewing and Distilling) in 1999 and 2000. He is also a member of MBAA and ASBC. He holds fellowships in IBD, the Institute of Biology, and the American Academy of Microbiology. He has more than 300 publications (books, patents, review papers, articles, and peer-reviewed papers) to his name. Upon retiring he established a consulting company, GGStewart Associates, with an office in Cardiff, Wales. He was awarded the IBD Horace Brown Medal in 2008, the ASBC Award of Excellence in 2008, the MBAA Presidential Award in 1983 and 1998, the MBAA Award of Distinction in 2009, and the Society of Industrial Microbiology Charles Thom Award in 1988.

27. Maintaining batch consistency with subsequent knock out brews. E. C. Baumann, Oskar Blues Brewery, Brevard, $\mathrm{NC}$

As breweries grow and expand, there comes a time when it no longer takes one brew to fill a fermenter, but several to fill one larger vessel. Knocking out multiple batches in the same fermenter quickly becomes standard practice. However, with multiple knock outs and extending total fill times, there are several factors that come into play to achieve the same flavor profile and product as is seen with single-fill batches. Batch consistency can be maintained by analyzing data collected from baselines established in each series of subsequent brews. If the appropriate baselines are not established or managed correctly, a finite fermentation curve and flavor profile is hard to achieve. This presentation will show process changes, analysis, and improvements made throughout the subsequent knock-out brewing process that equate to desired beer quality.

Eric C. Baumann is currently director of fermentation and quality control for Oskar Blues Brewery in Brevard, NC. He has been with Oskar Blues for more than four years. Within hi first few years at Oskar Blues, as cellar manager, Eric saw the growth of 70,000 bbl. He worked closely with brewhouse, lab, and plant managers to execute and achieve process improvements, plant expansions, and product quality control steps. In October 2012, Eric moved to Brevard, with a team of four others, to build and oversee the production of Oskar Blues newest brewery, which has an initial capacity of 50,000 bbl/year. He has previously worked at Uinta Brewing Co., Salt Lake City, UT, and Grand Teton Brewing, Victor, ID. Eric received his B.S. degree from the University of Utah in anthropology, with a minor in history. Eric started, as many do, home brewing on the side while pursuing a career in archaeology. Growing tired of archaeology and wanting to pursue a career in brewing, Eric got his foot in the door washing kegs at Grand Teton Brewing. Since then, he has been a part of several successful breweries and teams that have shaped his overall brewing background and passion to continue to push craft brewing further.

28. Genetics, ecology, and the diverse species Saccharomyces cerevisiae-Isolation of novel strains and lineages. R. J. Arnold, F\&R Distilling Co., Fort Worth, TX

The budding yeast Saccharomyces cerevisiae has been associated with human activity for several millennia due to its 
use in a variety of processes, including the fermentation of alcoholic beverages. The species has also been intensively studied in the laboratory, being used as a model organism for genetics and molecular biology. It was the first eukaryote genome to be sequenced, and its $12 \mathrm{Mb}$ genome is better annotated than any other eukaryotic organisms. The intensive research that surrounds $S$. cerevisiae has revealed surprising data that could prove groundbreaking with regard to the production of alcoholic beverages. In 2011, there were five known lineages of $S$. cerevisiae: wine/European, North American, Malaysian, West African, and sake. In the Western world, most industrial yeasts (brewing, winemaking, etc.) come from the wine/European lineage (Warringer et al., PlOS Genet., 2011). Data from the Warringer et. al. study revealed that each lineage possesses population-specific traits that are unique to one lineage. Traits (or phenotypes) result from the expression of an organism's genes, and genes control the expression of proteins that facilitate the catabolism of wort components into ethanol and aroma compounds. Therefore, it can be argued that population-specific traits among lineages could result in either the production of novel aroma compounds or the production of already known aroma compounds at strikingly different concentrations than are normally observed. In 2012, a Chinese expedition revealed eight new lineages of $S$. cerevisiae that were unknown to science: CHN I-CHN VIII. Interestingly, CHN I was revealed to be ancestral to all known lineages, making China the proposed origin of the species. If the argument that lineages contain population-specific traits is true, the discovery of eight new lineages could produce a wealth of novel aromas to be incorporated into alcoholic beverages. Furthermore, when one considers that the Western world has only utilized one lineage industrially, there are at least 11 lineages that could be explored for beverage production. Indeed, at least some of the lineages other than wine/European are suitable for beverage alcohol fermentation, with the sake and West African lineages being used for the production of sake and African being used for wines and beer, respectively. In 2011, Firestone \& Robertson's Head Distiller Rob Arnold isolated 11 $S$. cerevisiae strains from a Texas pecan nut. One of these isolates, nicknamed Brazos, is the strain used at the distillery today. Although there is a North American lineage, all the strains within this lineage are unable to metabolize maltose. Arnold's strain is very effective at maltose fermentation, leading him to believe that the strain could fit into an unknown or mosaic lineage. This oral presentation will cover topics on $S$. cerevisiae lineages, the potential of lineage diversity with regard to unique flavors in fermented beverages, and the data surrounding the Brazos strain pertaining to lineage and novel aroma compound production.

A native of Kentucky with a grandfather and multiple uncles who worked in the bourbon industry, Rob Arnold grew up surrounded by the distilling world. After graduating from the University of Tennessee with a bachelor's degree in microbiology, he enrolled in a Ph.D program in biochemistry at UT Southwestern Medical Center at Dallas, where he studied microbial fermentation and analytical chemistry. Two years into the Ph.D. program, he was contemplating leaving the medical research field to open a distillery. While in the early fundraising stages of pursuing that goal, he learned of the Firestone \& Robertson Distilling Co. from Fort Worth Souththe development group with which both he and $F \& R$ were working. Rob contacted $F \& R$ and learned that they were in need of a head distiller. After meeting with Leonard Firestone and Troy Robertson, and realizing they all had similar visions for bringing whiskey to Fort Worth, Rob left school early school with his master's degree and joined the F\&R team in 2011.

29. Automated quantification of budding Saccharomyces cerevisiae using a novel image cytometry method. L. L. Chan, D. J. Laverty, A. Kury, D. Kuksin, A. Pirani, and K. Flanagan, Nexcelom Bioscience, Lawrence, MA

Concentration, viability, and budding percentages of Saccharomyces cerevisiae are routinely measured in the biofuel and brewing industries. Measurement of these parameters is of great importance in a manufacturing setting because they can aid in the estimation of the product quality, quantity, and fermentation time of the manufacturing process. Specifically, budding percentages can be used to estimate the reproduction rate of yeast populations, which directly correlates with metabolism of polysaccharides and bioethanol production, and can be monitored to maximize production of bioethanol during fermentation. The traditional method involves manual counting using a hemacytometer, but this is time-consuming and prone to human error. In this study, we developed a novel automated method for the quantification of yeast budding percentages using Cellometer image cytometry. The automated method utilizes a dual-fluorescent nucleic acid dye to specifically stain live cells for imaging analysis of unique morphological characteristics of budding yeast. In addition, cell cycle analysis is performed as an alternative method for budding analysis. We were able to show yeast budding percentages that were comparable between manual and automated counting, as well as cell cycle analysis. The automated image cytometry method was used to analyze and characterize corn mash samples directly from fermenters during standard fermentation. Since concentration, viability, and budding percentages can be obtained simultaneously, the automated method can be integrated into the fermentation quality assurance protocol, which may improve the quality and efficiency of the bioethanol production process.

Leo Chan currently serves as the technology $R \& D$ manager and senior scientist at Nexcelom Bioscience LLC, Lawrence, MA. His research involves the development of instruments and applications for the Cellometer image cytometry system for detection and analysis of yeasts used in the brewing and biofuel industries. He is a member of MBAA. He received his B.S., M.S., and Ph.D. degrees in electrical and computer engineering from the University of Illinois at Urbana-Champaign (2000-2008).

\section{Engineering}

30. Pioneer wort boiling process with innovative internal calandria. T. Becher and K. Wasmuht, Ziemann International GmbH, Ludwigsburg, Germany

Modern wort boiling systems must work with individual process recipes, which can be divided into three phases: heating, simmering, and evaporating. To provide these three phases, an internal calandria usually relies on additional wort circulation pumps. Otherwise a huge effort is necessary for cleaning if the boiling time is increased and heat supply is damped down. The innovative design introduced here provides a solution without such disadvantages. It consists of two interconnected heating segments, each of which can be activated separately. The two segments reflect three boiling phases. The essential function is achieved by means of Venturi effects. The required product circulation can be combined with the lowest 
possible heat supply. The heating segment in use always operates in optimum heating-flow conditions. Simmering can be introduced as a rediscovered procedure. A series of tests was performed in a pilot brewery to prove functionality. In 2013 two breweries with a cast out wort of approximately $80 \mathrm{bbl}$ successfully installed the novel equipment. Using the same occupancy time, a lower evaporation rate can be achieved, the tendency to fouling can be reduced, and thus, product quality (TBI, free DMS, DMS precursor, protein fractions, aroma profile) can be maintained. Moreover, an efficient use of energy can be achieved. The presentation describes the novel calandria design, the respective process technology, and the technological results in practice.

Tobias Becher graduated as a diploma engineer of brewing science and beverage technology in 2001 from the Technical University of Munich in Freising-Weihenstephan (Germany). He apprenticed as a brewer and maltster before, worked afterward as a process engineer for beer filtration systems, and later worked as a technical consultant for environmental issues in the brewing sector. Since 2005 he has been employed by Ziemann. Today he is head of research and development within the Process Technology Division at Ziemann International GmbH (Germany).

31. From barley to the glass-Create your own beer. J. Binkert, J. Lauer, D. Haertl, and J. Preiß, Kaspar Schulz, Bamberg, Germany

Until the middle of the last century the malthouse was an integral part of many breweries. Thus, brewers were able to control all technical and technological operations. Nevertheless, at least in Germany, the professional title is still "brewer and maltster." As a result of this capability brewers could directly affect the characteristics and quality of their malts, which led to an unlimited variety of types and flavors. Currently, the trend toward individualization of beers is experiencing a strong revival, but at the moment, brewers are depending on the raw materials offered by the markets, with all that implies. The history of the 336 year old company Kaspar Schulz contains chapters where malting technology played a big role. Already at the beginning of the last century machinery for malthouses was produced in Bamberg. This technology should be recovered and adapted to the current needs of brewers and maltsters. For this purpose a compact malting plant was developed by Kaspar Schulz. The system includes the needed ventilation technology and fits into an area of just $20 \mathrm{~m}^{2}$ for an output of 2 tons/week. The largest drum is designed for a maximum output of 25 tons/week. The process steps steeping, germination, and kiln-drying are automatically operated in a drum system and a consigned steep. Careful conveying and gentle agitation are realized by the slow rotation of the drum in combination with an integrated screw conveyor. Modern manufacturing technologies guarantee an optimized hygienic design of the plant. Besides compact construction, the modularity of the system offers many advantages. Thus, the system can be easily expanded, e.g., by a further drum for germination and kiln-drying. This additional drum may use the existing steep, the burner and glass tube heat exchanger of the ventilation system, as well as the handling and processing equipment for grain and malt. All process steps are fully automated and customizable. It's possible to produce all common types of malt. In combination with the handling and processing equipment for grain and malt, the brewer can independently create his own product from corn stalk to the glass. The prototype of this system was successfully tested at the beginning of this year at Kaspar Schulz in Bamberg. The results of this research project, as well as the easy use of this system, will be presented in this work.

Johannes Preiß' career in brewing began in Weihenstephan, Germany, where he studied at the Technische Universität München. Johannes graduated with a degree in brewing and beverage technology. He started working in 2008 at Krones AG, Germany, as a project manager in the Research \& Development Department. The main focus of his work was brewhouse and cleaning technology, as well as energy optimization. His main topics were lautering technology and integration of solar heat into breweries. As a result of his work, Johannes published several patents and scientific papers. Since the end of 2012 he has been working as the technical director for Kaspar Schulz, Bamberg, Germany. Besides his profession, Johannes is a talented musician. In 2009 he received the cultural award from the City of Nuremberg, Germany.

32. Engineering and design of brewery water deaeration systems. D. Duff, FleetwoodGoldcoWyard, Romeoville, IL, and J. Brickel, FleetwoodGoldcoWyard, St. Louis, MO

This paper covers the basic principles involved in deaerating water. Based upon these principles, this paper details the critical design parameters that need to be taken into consideration by brewers to help identify the operational specifications they need to be aware of for ensuring the right design. There are different technologies available for controlling dissolved oxygen. This discussion will identify the options and describe their benefits, capabilities, and limitations. A relatively comprehensive review of selection of components, determination of the level of automation, and considerations that need to be taken into account for properly integrating the deaeration system with existing brewery operations will be covered. Finally, an estimate of the costs associated with purchasing and installing a brewery water-deaeration system is provided to help brewers budget for this improvement.

David Duff has been a member of MBAA since 1982 and has held positions in his local district, as well as contributed on the Technical Committee as an organizer and session moderator. He has presented at MBAA Annual Conferences on several occasions, covering brewery pasteurization technologies. David began his career with Labatt Brewing Company in Canada. In 1997 David left Labatt to join forces with the Stroh Brewing Company as director of packaging operations. He now holds the position of North American sales executive with FleetwoodGoldcoWyard, part of the Barry-Wehmiller Group of Companies, where he specializes in brewery process equipment technologies.

33. An economical brewery temperature control and monitoring system built using commercially available components. A. Debower and K. DeBower, Austin Beerworks, Austin, TX

Brewery temperature control systems are often expensive and uni-dimensional, i.e., capable of consistent control but incapable of remote control and monitoring. Existing commercially available integrated systems are expensive and inflexible. Austin Beerworks has developed a flexible system that utilizes a standard PC, freeware programmable software, and readily available PLC and other hardware components to monitor and control the temperature of all fermentation ves- 
sels, brite tanks, and hot and cold liquor tanks. Further brewery process monitoring and control has been integrated into this system with minimal additional capital expenditures. All components are readily available, with the exception of a simple signal conditioning device that was fabricated in-house. Analog data are fed from the temperature probes (Johnson Controls A99-B) to the signal conditioners, which in turn are processed by analog-to-digital (A/D) converters and ultimately interpreted by a PLC. The PLC controls the opening and closing of glycol valves at the tanks or steam valves in the case of the hot liquor tank, and a positive confirmation mechanism feeds back glycol valve position information to the PLC. Temperature probes, glycol control power, and glycol valve position data are all connected to the PLC via a CAT 6 data cable that consists of 4 twisted pairs of 23 AWG wire. The PLC is programmed and monitored by a server running on Microsoft Server 2008 via machine-to-machine (M2M) programmable freeware, and all data are archived and searchable on the server. The server and PLC are physically connected via local area network (LAN) and RS-232. The data and control features are made available via any Internet browser and on any computer or device with Internet connectivity anywhere in the world. Programming is accomplished in-house and can be augmented to add or subtract functionality as needs change. Data returned from the tanks are constantly monitored for noise or unusual values, and the program actively monitors for such anomalies and alerts plant management when any occur. Other processes that have been added include automatic hot liquor tank filling and recirculating during heating, brewhouse and cellar pump control, flow meter monitoring, and various packaging counting processes. Archived data are exportable to Microsoft Excel and Quickbooks.

Adam DeBower is co-founder and co-owner of Austin Beerworks, a canning craft brewery in Austin, TX. In addition to managing fermentation, filtration, and packaging operations, Adam spends a large amount of his time maintaining brewery physical plant systems and special project procurement and installation. Adam worked at Flying Dog Brewery in Frederick, MD, and at Real Ale Brewing in Blanco, TX, prior to founding Austin Beerworks. A native Texan, Adam was born and raised in Austin and is an alumnus of Baylor University.

\section{Yeast, Fermentation, and Microbiology}

34. The effect of platelet-activating factor on yeast attenuation. P. Callihan and W. E. Roudebush, University of South Carolina School of Medicine Greenville, SC

Studies have reported that beer (moderate consumption) can have a positive impact on health and disease prevention (reviewed in Beer in Health and Disease Prevention, V. R. Preedy, ed., Academic Press, London, 2009). Additionally, there is emerging evidence demonstrating the antioxidant capacity of beers (Zhao et al., J. Sci. Food Agric. 93:910-917, 2013). The health benefits of beer may be tied to its overall quality. Beer quality is strongly influenced by the biochemical performance of yeast (Saccharomyces cerevisiae) during fermentation, with performance defined as the capacity of yeast to exhibit cell growth, attenuation, flocculation, and flavor. A number of biochemical compounds are produced by yeast, including lipids. Yeast lipids have a substantial influence on beer quality due to sterol synthesis controlling yeast growth. In particular, yeast cells synthesize a unique and novel lipid, i.e., platelet-activating factor. Platelet-activating factor
(1-O-alkyl-2-O-acetyl-sn-glycero-3-phosphorylcholine; PAF) is a potent signaling phospholipid that appears to be critical for many of the events surrounding cell development and metabolism. Yeast synthesis of PAF appears to control the cell cycle phase in budding yeast. In a preliminary study, we described temporal PAF production in ale and lager yeast at different culture temperatures (Roudebush et al., Am. J. Brew. Chem. 64:135-138, 2006). Little information is known on the direct impact PAF has on the physiological biochemistry of yeast. Therefore, the study objective was to determine the effect of exogenous PAF on brewer's yeast ( $S$. cerevisiae) attenuation. A proprietary strain of brewer's ale yeast (No. 1028; Wyeast Laboratories, Inc., Odell, OR) was cultured in sterile dried malt extract (DME; $13.8^{\circ} \mathrm{P}$; Crosby and Baker, Westport, MA) in water. Individual static yeast cultures $(50 \mathrm{~mL}$ total volume; $5 \mathrm{~mL}$ head volume) were anaerobically incubated at $20^{\circ} \mathrm{C}$. Samples $(500 \mu \mathrm{L})$ of yeast-conditioned DME culture media were obtained at specific intervals $(0,24$, and $48 \mathrm{hr}$ of culture), and specific gravities $\left({ }^{\circ} \mathrm{P}\right)$ were measured by refractometry (Grand Index, Hong Kong; model RSG-100/ATC) and recorded. There was a significant difference $(P<0.05)$ between the control $\left(5.8^{\circ} \mathrm{P}\right)$ and PAF $\left(4.6^{\circ} \mathrm{P}\right)$ group attenuation at $24 \mathrm{hr}$. At $48 \mathrm{hr}$ (final attenuation), differences between the control $\left(4.8^{\circ} \mathrm{P}\right)$ group and the PAF $\left(4.6^{\circ} \mathrm{P}\right)$ group approached significance $(P=0.065)$. The data demonstrate that brewer's yeast responds to PAF with a lower attenuation and in a shorter time period. Additional studies are warranted to determine the impact of PAF on yeast fermentation time (potentially increasing beer production throughput efficiency) and attendant beer quality.

Phillip Callihan completed his Ph.D. degree in pharmaceutical and biomedical sciences at the University of Georgia in 2012 and is currently pursuing an M.D. degree at the University of South Carolina School of Medicine Greenville. He is a member of the American Society of Pharmaceutical Scientists and the American Medical Association. In 2011, he delivered an invited talk at the Southeastern Regional Lipid Conference titled "Distinct Generation, Pharmacology, and Distribution of Sphingosine 1-Phosphate and Dihydro-sphingosine 1-Phosphate in Human Neural Progenitor Cells." Phillip has authored multiple biochemistry and pharmacology publications and is now investigating the potential roles of beer in improving human health.

35. Operating a secondary location for barrel-aged wild and sour beer production. C. Yakobson, Crooked Stave Artisan Beer, Denver, CO

The ability to segregate processes that could pose potential hazards for contamination has always been crucial in the brewery setting. In large breweries that could mean physical separation via different levels of production or storage spaces that are adequately confined. To many medium-large to smaller brewers, introducing wild yeast and bacteria poses a threat that is not always visible, and the segregation of equipment can be tedious. Building and operating a secondary off-site location is commonplace when it comes to cold storage of the finished product. The off-site model poses a solution for the conscious brewery looking to separate wild and sour beers from production beers. The dramatic increase in wild and sour beer production is evident in every size brewery, and the secondary location model poses a solution for breweries looking to branch out and maintain consistency, while still having the ability to not tie-up production space with barrels and wild 
yeast. This presentation covers the considerations for running an off-site barrel warehouse from initial start-up and equipment considerations to daily operations and considerations for transport and scheduling.

Chad Yakobson is the owner and director of operations of Crooked Stave Artisan Beer Project in Denver, CO. After initially studying winemaking in New Zealand, Chad switched his focus to the brewing industry, concentrating on various microorganisms present during barrel aging of sour beer. In 2010 Chad completed his master's thesis, "Primary Fermentation Characteristics of Brettanomyces Yeast Species and Their Use in the Brewing Industry," and was awarded an M.S. degree in brewing and distilling from Heriot-Watt University and the International Centre for Brewing and Distilling in Edinburgh, Scotland.

36. Innovations in antimicrobial tubing eliminate bacteria and biofilm growth in closed draught systems and brewery environments. B. A. Coulson and G. Kinney, Eldon James Corp., Denver, CO

In the brewing environment, there are a few microorganisms capable of growing in and deteriorating beer. Four industry isolates were found to be most common in the formation of biofilm in beer dispensing and brewing environments. These include Acetobacter lovaniensis, Wickerhamomyces anomalus, Lactobacillus brevis, and Pseudomonas aeruginosa. The presence of these beer spoilers gives insight into the hygiene conditions of a brewery or dispensing system. Biofilm growth is common on equipment components and in niches that are difficult to clean. They come in contact with the product and provide ideal growth conditions for a multitude of germs that affect flavor, aroma, and the overall quality of beer. Utilizing a breakthrough in silver ion technology, a newly developed PVC-free tubing co-extruded with a silver lining has been verified to be effective against these top four beer-spoiling bacteria and the growth of biofilm. Third-party test results have proven that this new innovation is capable of reducing the concentration of all the selected biofilm microorganisms by up to $100 \%$ over a $24 \mathrm{hr}$ test period.

Gregory W. Kinney has been with the Eldon James Corporation for one year. His primary role has been to expand precision manufacturing to the food and beverage markets. Greg has seven years of experience in the beer industry, with a deep knowledge of draught systems and quality challenges for on-and off-premise accounts. He has served in many rolls, including draught system quality assurance, brand development, and sales management

\section{Relationships between dry hopped beers and diacetyl} formation. K. M. Taylor, White Labs, Inc., San Diego, CA

Far too often people are encountering diacetyl in beers made today. Many times, diacetyl is found in beers that should stylistically have zero: pale ales, India pale ales, and double IPAs. This style of beer, typically fermented with a clean profile yeast strain, should have no diacetyl present, and yet more and more cases are being found with a plethora of diacetyl. One untested theory of the source of excess diacetyl is the relationship between the fermentation and the addition of hops after fermentation begins. What is the interaction between added hops and krausen? Are hops helping with the transition from acetolactate to diacetyl? Using controlled fermentations and gas chromatography, we can make some determinations about when diacetyl is forming and suggest how it can be prevented in dry-hopped beers.
Kara Taylor received a B.S. degree in biology from Loyola Marymount University in Los Angeles, CA. She began employment at White Labs in San Diego, CA, in 2009 as a yeast laboratory technician. Since 2011, she has functioned as the analytical laboratory specialist in White Lab's analytical laboratory. She is a member of MBAA and ASBC and serves on multiple subcommittees.

\section{Finishing and Stability}

38. Beer filtration-Present and future. F. Scheer and M. Skroblin, Krones, Inc., Franklin, WI

Beer filtration is inherently a balancing act. Precoat filtration technology is the most widespread method of filtration used. It has been developed over the last decades into an increasingly efficient filtration technology. We have to discuss the removal of haze particles, haze-producing substances, and removal of organisms. Filtration must be tight enough to remove these unwanted components, without losing the essential quality of the beer filtered. It is the unique design of powder filters, and the twin flow system (TFS) filter in particular, that allows for the use of many types of filter aids, including replacements for kieselguhr, some of which are being researched or are close to market release. In powder filtration, the brewing industry has relied on a proven, effective, and flexible system, with a high flux rate producing high-quality results.

Fred Scheer graduated in 1976 from Doemens Brewing Academy (Munich, Germany) with a brewmaster's degree in brewing and malting. He worked at several breweries in Europe before emigrating to the United States in 1983 to help establish Capital Brewery in Madison, WI. Later, he was technical director for the Frankenmuth Brewery, a 50,000 bbl brewery in Michigan. He also worked for Pabst Brewing in Milwaukee, WI, in corporate brewing and for their China operation. In 2011 Fred accepted the position of director of brewing and process technology with Krones Inc. in Franklin, WI.

39. New approach in beer clarification with the focus on precoat filtration. J. Zacharias, Krones AG, Neutraubling, Germany

Precoat filtration technology is the mostly widely used method of filtration. It has been developed over the last decades into a highly efficient filtration technology. In addition, when compared with alternative filtration methods it has advantages, especially in its variability with regard to malt quality influenced filtration problems and also with regard to cost minimization. More than $80 \%$ of beer clarification is done using precoat filtration with kieselguhr as the filter aid. Its handicap is the increasing demands associated with disposal of kieselguhr. Changing legislation is leading to strong requirements, especially in central Europe. This uncertainty is unsettling the brewing guild. Starting with well-developed precoat filtration, possibilities, limitations, and alternatives must be discussed. This is forcing increasing engagement in finding the best alternative processes or media for kieselguhr. All the previously applied alternative techniques have in common is that they cannot deliver the same technological flexibility with the same technological and sensory quality over the whole process. Breweries with a wide variety of products, in particular, will have this main objection to performance. As a main focus, therefore, the well-proven Krones technology, the twin flow system, is an ideal exceptional base for using alternative filter aids. A new approach will be presented and discussed 
with regard to the following aspects underlined by the expertise provided by the last year's work. In the development of new strategies to substitute for the kieselguhr filtration process the approach is driven by the quality of filtrate, flexibility due to malt quality and raw materials, harmlessness of possible filter aid, disposal, energy consumption, and adaption to manpower. In summary, sustainability has to be considered.

As a student of food technology in Weihenstephan, Joerg Zacharias obtained his doctorate at TU in Munich in the Chair for Fluid Mechanics and Process Automation. It was there that he also lectured for several years on food process technology and measurement technology used in biotechnology. He has been an employee of Krones AG since 2005, working in the $R \& D$ Process Technology Division for the beer, water, milk and juice sectors. As an expert on rheological and process engineering issues, as well as on the requirements of hygienic design in process technology, Joerg plays an important role in the current development projects performed at Krones AG.

40. Direct oxidation of amino acids-An unrevealed pathway leading to the formation of staling aldehydes in bottled beer? P. C. Wietstock, T. Kunz, and F. J. Methner, Technische Universität Berlin, Berlin, Germany

Off-flavor in lager beer is often associated with the appearance of staling aldehydes such as 3-methylbutanal, 2-methylbutanal, methional, phenylethanal, and benzaldehyde. Previous storage experiments revealed that elevated concentrations of Fe and oxygen promote the rate of beer flavor staling. Known mechanisms, such as Strecker degradation of amino acids, alone give no explanation for this phenomenon. Additional storage trials were conducted to further assess this observation. A commercially available lager beer was dosed with varying level of amino acids and $\mathrm{Fe}$, respectively, and stored over a period of 6 months (dark, $28^{\circ} \mathrm{C}$, with and without oxygen in headspace). Bottles without additions served as references. Staling aldehyde levels were measured during storage via SAFE-GC/MS, and oxidative beer stability was determined using electron spin resonance (ESR) spectroscopy. The experiment confirmed that staling aldehyde levels in bottled beer positively correlate with both amino acid and Fe levels and are increased by the presence of oxygen. Bench trials using model solutions (acetate buffer, $\mathrm{pH} 4.3,5$ vol.-\% EtOH) revealed that oxidation of leucine, isoleucine, and phenylalanine via $\mathrm{Fe}$ $\mathrm{H}_{2} \mathrm{O}_{2}$ yields 3-methylbutanal, 2- methylbutanal, phenylethanal, and benzaldehyde, respectively. Furthermore, radical concentration as measured using ESR spectroscopy directly correlated with the formation of these aldehydes. A so far unrevealed staling mechanism via direct oxidation of amino acids by hydroxyl radicals in bottled beer is proposed.

Philip Wietstock is a scientific assistant at the Technische Universität Berlin, Germany. After graduating with a Dipl.Ing. degree in biotechnology from the Technische Universität Berlin (2009), he worked for one year as an intern at the Department of Food Science and Technology at Oregon State University, Corvallis, OR. In 2011, he transferred to his present profession, where he is working on his dissertation, for which he is investigating parameters influencing oxidative beer stability.

41. Are U.S. brewers ready for beer membrane filtration (BMF)? R. Schuurman, Pentair Haffmans, Venlo, The Netherlands
The filtration of beer with membrane filters is gaining a serious foothold in beer markets worldwide. Brewers recognize the advantages of this relatively new technology. From the perspective of beer quality, membrane filtered beer is consistently and significantly better for turbidity, physical/chemical stability, and taste stability. Next, by eliminating diatomaceous earth (DE), disposal and health issues are no longer a concern for the brewery. The operation of membrane filtration is simple and straightforward, with very short stop-start-stop times and fast brand changes. In addition, CAPEX and OPEX are competitive, especially with the new BMF compact unit. Beer membrane filters (BMF) have been on the market for more than 10 years. In the first quarter of 2013, Pentair wrote its 50th order for a BMF, but no U.S. brewery has a BMF installed even though U.S. breweries produce about $10 \%$ of the world's beer. In this presentation the latest BMF design will be discussed, along with the results of an analysis on how BMF, and especially the new compact unit, fits into the U.S. brewing industry. In addition, misconceptions like the need for a centrifuge and compatibility to stabilization methods will be discussed.

Rik Schuurman has more than 25 years of experience in the brewing industry and has been a senior process engineer at Pentair since 1999. He is a brewmaster specializing in the design and engineering of all kinds of brewery systems. For the last 10 years, his work has focused on beer membrane filtration as an alternative to diatomaceous earth filtration.

\section{Hops}

42. Factors influencing the losses of bitter substances and possibilities to increase the yield during brewing. F. J. Methner, T. Kunz, and M. Marinoff, Technische Universität Berlin, Berlin, Germany

Bitter substance utilization during conventional beer production is quite low and still a major problem for the brewing industry. Brewing trials were conducted to evaluate the effect of $\mathrm{pH}$ and iron on bitter substance yield. In addition to fermentation trials, hopped and unhopped worts with and without iron addition were adjusted to different $\mathrm{pH}$ values. Bitter substance yield was significantly influenced by both $\mathrm{pH}$ and iron concentration. Acidifying the system yielded reduced bitter units, hop acid, and iron concentration. Regardless of the initial $\mathrm{pH}$, bringing the $\mathrm{pH}$ to alkaline conditions again caused the highest results. Iron content in unhopped wort was unaffected by $\mathrm{pH}$ adjustment. The results suggest that reversible, $\mathrm{pH}$-dependent hop-acid-iron complexes are formed and are mainly responsible for the loss of bitter substances during fermentation. Additional trials are presented that demonstrate that the outcomes of this research can be used to recover hop acids from hot trub.

Frank-Jürgen Methner conducted studies in brewing science at Berlin Institute of Technology (TU) from 1975 to 1981. After the studies, he began working as an operating supervisor at the Schlösser Brauerei, Düsseldorf. From 1982 to 1986, he was a scientific assistant with teaching duties at TU Berlin. Research projects and Ph.D. thesis, "Aroma Formation of Berliner Weissbier with Special Focus on Acids and Esters," were further tasks. For 18 years, starting in 1987, he held a leading position as a director at the Bitburger Brauerei, Bitburg, Germany, with responsibilities in fields such as research and technology, as well as quality assurance. Beginning with the winter semester 2004/2005 he took over the Chair of Brewing Science within the Department of Biotechnology at Berlin Institute of Technology (TU Berlin). 
43. Evaluation of the brewing properties of the new German hop varieties. A. Gahr, Hopfenveredlung St. Johann GmbH \& Co. KG, Train-St. Johann, Germany, and A. Forster, HVG Hopfenverwertungsgenossenschaft e.G., Wolnzach, Germany

The brewing properties of new hop varieties, once registered, are mostly evaluated empirically, although systematic trials are often missing. This applies also to four new German varieties, the so-called "flavor hops": Mandarina Bavaria, Polaris, Huell Melon, and Hallertau Blanc. The 2012 crop is the first crop to provide hops from the four new varieties from mature plants harvested using standard picking methods. These were used to conduct all malt lager brewing trials with brews of $2 \mathrm{hL}$ each together with established varieties. Apart from an extensive analytical characterization of all hop-relevant ingredients in hops and beers, sensory evaluations also were performed. The results cover the following principal points: the general brewing properties of the hops, particularly their influence on bitterness and the flavor of single-variety beers; the character and suitability of the varieties for dry-hopping and comparison to their late-hop aroma; comparison of aroma, flavor, and bitterness of the new varieties to their established counterparts (late- and dry-hopping); the stability of late- and dry-hop aroma; and the transfer rates of aroma substances and polyphenols from hops to beer (late- and dry-hopping).

Andreas Gahr was trained on the job as a brewer and maltster at the Augustiner Brewery, Munich, Germany. He received a brewmaster degree from the Technical University MunichWeihenstephan in 1994 and worked for another four years at the university for the Chair of Brewing Technology I. Since 1998 Andreas has been the head of the Research Brewery St. Johann, which belongs to the hop processing company Hopfenveredlung St. Johann $\mathrm{GmbH} \& \mathrm{Co}$. KG and deals with all kinds of hop-related brewing trials and product development, as well as technological and raw material trials for suppliers and the entire brewing industry. Together with his co-authors he received the MBAA Inge Russel Best Paper Award in 2010.

44. The effect of kilning air temperature on hop essential oil content and aroma. T. P. Nielsen, Sierra Nevada Brewing Co., Chico, CA, V. Peacock, Hop Solutions, Inc., Edwardsville, IL, S. Garden, John I. Haas, Yakima, WA, and P. Smith, Loftus Ranches, Moxee, WA

During the 2012 hop harvest, the craft brewers hop quality group (HQG) conducted a study focusing on drying air temperature and aroma quality of dried hops. The commercial method of drying hops in the United States utilizes an upward flow of dry, heated air through a single tier, or bed, of hops. Variables, such as air velocity, air moisture content, bed depth, and air temperature contribute to the effectiveness of drying and the resulting aromatic, physical, and storing properties of dried hops. The effects of air temperature were studied in two hop varietals and two hop kilns located in the Yakima Valley in Washington. The primary goal of the study was to gauge the overall quality effect of drying hops at 130 and $150^{\circ} \mathrm{F}$. Results show a wide range of moisture contents from the bottom to top bed heights in both 130 and $150^{\circ} \mathrm{F}$ dried hops; however the stratification was significantly greater in $150^{\circ} \mathrm{F}$ dried hops. The total essential oil content for Citra hop samples showed greater losses in the bottom and middle third of the drying beds, whereas Cascade samples were uniform in total essential oil content throughout the drying bed depth. A statistically significant number of samples was analyzed by SPME-HSGCMS, along with multivariate analysis, inferring quality implications of drying hops at $130^{\circ} \mathrm{F}$ versus $150^{\circ} \mathrm{F}$. Caryophyllene oxide proved to be an excellent marker for oxidation incurred by the drying method. Qualitative measurements of caryophyllene oxide, as well as other volatile hop components, are greatly elevated in $150^{\circ} \mathrm{F}$ hop kiln samples compared to $130^{\circ} \mathrm{F}$ hop kiln samples. These results outline some major differences produced by varying air temperature when drying hops. Further study of the brewing quality of hops dried at low and high temperatures is needed in a follow up of this study.

Thomas (Tom) Nielsen has been working in an $R \& D$ capacity at the Sierra Nevada Brewing Company for more than nine years. Much of his work has involved basic and applied flavor research on hops and malt. Prior to starting his career at Sierra Nevada, Tom obtained a B.S. degree in food science and technology from Rutgers University, focusing on food chemistry. Tom is currently the technical chair of the Hop Quality Group, as well as Sierra Nevada's representative to the Hop Research Council, American Malting Barley Association, and Brewing and Malting Barley Research Institute.

45. Dry hopping perspectives and beer stability. T. Becker, Technische Universität München, Freising, Germany

Dry hopping, the addition of hops in the fermenting or lager cellar, in the United Kingdom is, and for about 25 years in the United States, widely used and enjoys increasing popularity in Germany as well. Until now dry-hopping has barely been investigated scientifically. For dry- hopping many different methods are used that differ mainly in terms of their technical complexity, the raw material (pellets or cones) used, contact time, and temperature. Each method has its own characteristic and raises a plethora of issues and problems and often brings classic beer analytics to their limits. The focus of our study was to compare in a first step different hopping techniques regarding their ability to dissolve hop components like hop oils, polyphenols, and bitter substances. In a second step we systematically investigated how dry-hopping effects beer haze. In addition, the investigation of aging and flavor stability of dry-hopped beer was part of the focus of our work. The aim was to get answers about the stability of hop aroma and the masking effects of hop aroma in beer aging.

Thomas Becker is currently a full professor and the head of the Institute of Brewing and Beverage Technology (Lehrstuhl für Brau- und Getränketechnologie) at the Technische Universität München, Weihenstephan. From 1986 until 1991 Thomas performed academic studies on the "Technology and Biotechnology of Food" at the Technische Universität München. He finished his Ph.D. there on "Development of a Computerized Enzyme Integrated Flow Line Injection System and Its Application in Biotechnological Process Control Engineering and Quality Control.” From 1996 until 2004 he worked as an assistant professor at the Chair of Fluid Mechanics and Process Automation at the Technische Universität München, Weihenstephan. With the topic "Management of Bioprocesses by Means of Modeling and Cognitive Tools" he completed his habilitation in 2002 and graduated with "Venia Legendi" in the field of bioprocess engineering. In 2005 he was appointed to a full professorship at the Chair of Process Analysis and Cereal Technology at the Universität of Hohenheim, Stuttgart, where he worked in the field of process analysis. In 2009 the Technische Universität München appointed him to a full pro- 
fessorship of the Institute of Brewing and Beverage Technology in Weihenstephan. He is a member of several scientific boards and committees, as well as government organizations for food and beverage issues.

\section{Malt and Grains}

46. Accelerated malting using elevated steeping and germination temperatures with a focus on malt quality and homogeneity. C. Mueller and F. J. Methner, Technische Universität Berlin, Berlin, Germany

Production of malt is a time and energy consuming process. Time savings during malting, thus, are advantageous for maltsters, but the resulting malt quality and homogeneity must stay in the range of the brewer's specifications. The literature suggests relatively low temperatures should be used during steeping and germination $\left(13-17^{\circ} \mathrm{C}\right)$ to produce malts with a high quality. In these investigations, constant steeping temperatures between 15 and $35^{\circ} \mathrm{C}$ were used. Up to 25 and $30^{\circ} \mathrm{C}$, faster germination rates, higher germination energies, and improved malt qualities, as well as increased malt homogeneities, compared with a "normal" temperature of $15^{\circ} \mathrm{C}$ could be achieved. Furthermore, trials with germination temperatures between 16 and $28^{\circ} \mathrm{C}$, whereby green malt samples were taken at the third to six germination day, resulted in a faster attainment of similar or better malt qualities up to $24^{\circ} \mathrm{C}$ depending on barley variety. Time savings of about 1.5 processing days are possible using high steeping and germination temperatures and also are necessary to compensate for the extract losses due to accelerated growth. The outcomes of this research could have big benefits for future malting procedures and could change the view of suggested low temperatures during malting, which may not be completely relevant using modern barley varieties and malting process parameters.

Christian Mueller apprenticed as a brewer from 1998, followed by employment as a brewer and assistant in quality control at the Tuborg/Carlsberg brewery, Mönchengladbach, Germany. Afterward, he studied brewing technology at the Technische Universität Berlin from 2002 to 2008, including student jobs on several research projects. Since qualifying for his engineer degree he has been working as a scientific assistant in the Department of Brewing Science at TU Berlin.

47. Influence of special malt and coloring agents on the oxidative beer stability and aging components. T. Kunz, T. Stoffregen, C. Cruz Palma, C. Xu, and F. J. Methner, Technische Universität Berlin, Department of Food Technology and Food Chemistry, Chair of Brewing Science, Berlin, Germany

The effects of special malt and coloring agents on oxidative beer stability and flavor during storage are controversially discussed in the literature. The Maillard reaction products generated by high temperatures during kilning or roasting of malt and then further by boiling processes are jointly responsible for the characteristic color and flavor of the final beer. Due to their complexity, these products can participate in numerous reactions during brewing and beer storage. Thanks to our previous investigations using roasted/color malt or the addition of caramel color and roasted malt beer in the brewing process, it was possible explain the contradictory interpretation of the influence of specific intermediate Maillard reaction products with a reductone/endiol structure on reduction power and prooxidative activities. Novel investigations using ESR spectroscopy (EAP and T values) and different methods for the determination of reduction power or potential (Chapon, MEBAK) demonstrate the correlation of two significant key factors in special malt and coloring agents that are responsible for the effects on oxidative beer stability. One is the extremely high iron entry caused by the significant iron release from malt during the kilning and roasting process. The second factor arose from the strong reduction properties of specific Maillard reaction products with a reductone/endiol structure that can rapidly reduce oxidized metallic ions such as $\mathrm{Fe}^{+3}$ to $\mathrm{Fe}^{+2}$. Both factors are responsible for an acceleration of oxygen activation and intensification of the Fenton-Haber-Weiss reaction system. Consequently, an acceleration of oxidative processes and a stronger radical generation of very reactive radicals $(\mathrm{OH})$ can be observed in the wort and beer matrix. This fact results in a faster consumption rate of specific antioxidative substances such as $\mathrm{SO}_{2}$ and, thus, lower oxidative beer stability indicated by the decrease of the EAP value and a stronger increase in specific aging compounds during storage, especially typical oxidation indicators like 3-/2-methylbutanal, phenylethanal, etc.) analyzed via GC-MS. Altogether the results present the influence of the reduction power and pro-oxidative effects of special malt and coloring agents like caramel color, roasted malt beer in the wort, and beer matrices. Additionally, the study gives advice on how to reduce or respectively avoid the pro-oxidative effects through optimized handling during the brewing process or the use of alternative coloration substances to adjust beer color.

After qualifying as a certified technician in preservation engineering (1991-1993), Thomas Kunz completed his basic studies in chemistry at the University of Applied Sciences, Isny (1994-1995), and his basic studies in food chemistry at Wuppertal University (1995-1998), before starting to study food technology at the University of Applied Sciences, Trier (19982002). After graduating, he worked as a chartered engineer in the area of ESR spectroscopy at the Institute of Bio Physics at Saarland University (2002-2004). Since 2005, he has been employed as a Ph.D. student at the Research Institute of Brewing Sciences, Berlin Institute of Technology (Technische Universität Berlin). His main research focus lies in analyzing radical reaction mechanisms in beer and other beverages using ESR spectroscopy.

48. Analysis of wort sugars using fluorescent biosensors. J. Akerboom, J. S. Marvin, and B. Basanta, HHMI, Janelia Farm Research Campus, Ashburn, VA, M. Hagerman, Lost Rhino Brewing Company, Ashburn, VA, and L. L. Looger, HHMI, Janelia Farm Research Campus, Ashburn, VA

The most routine measurements performed in the brewing industry are gravity measurements of unfermented wort and (fermenting) beer. These measurements give the brewer a value, expressed either as Plato, Brix, or dimensionless (specific gravity). This value is directly related to the percentage of extract per weight of the liquid (mainly the concentration of dissolved carbohydrates) and is an essential parameter to assess the status and potential of the product. However, this value is a sum of several different compounds and does not give insight into the actual composition and concentration of each fermentable sugar in the wort or beer. Worts giving identical gravity readings can differ widely in composition, due to use of different malts, adjuncts, and mashing regimes. Current methods (HPLC, enzymatic assays, biosensors) to determine wort and beer composition are expensive and laborious. Here, we will present a complete set of protein-based fluorescent biosensors to measure wort sugars. Each of these has a high affinity for either glucose, maltose, or maltotriose-the three 
most abundant carbohydrates in wort. We will describe the design and development of these biosensors in detail and give examples of commercial applications. These sensors give direct accurate insight into wort composition and fermentability potential, are less laborious to use than current HPLC and enzymatic assays, and show great promise for the commercial brewing industry.

Jasper Akerboom received his B.S. degree in molecular sciences from Wageningen University in The Netherlands. During his following M.S. research, he worked for a year at Sheffield University, U.K., on the crystallization and structure determination of proteins involved in glycolysis and gluconeogenesis in the lab of David W. Rice. Afterward, he returned to Wageningen University and joined the lab of John van der Oost in the Department of Microbiology and identified and characterized the gluconeogenic enzyme fructose-1,6-bisphosphatase from the hyperthermophile Pyrococcus furiosus. He stayed with the Department of Microbiology at Wageningen University for his Ph.D. research, where he studied enzymes and structural, binding, and regulatory proteins involved in carbohydrate metabolism in hyperthermophilic life under the supervision of Willem M. de Vos and John van der Oost. After receiving his Ph.D. degree in food science and nutrition in 2007, he joined the lab of Loren L. Looger at Howard Hughes Medical Institute in Ashburn, VA, where he was responsible for the development of fluorescent biosensors for in vivo brain activity detection. Since January 2013, he is also a part-time laboratory manager at Lost Rhino Brewing Company in Ashburn, VA. Jasper has published more than 30 peer-reviewed articles and book chapters.

49. A new beer design tool-Use of Malt-Aroma-Wheel for the prediction of beer characteristics. J. Voigt, University Trier, Trier, Germany, and A. Richter and T. KrausWeyermann, Weyermann Specialty Malts, Bamberg, Germany
The development of the Malt-Aroma-Wheel allows new approaches for generating new beer styles and recipes. The definition of a malt mixture of various specialty malts and consideration of the original gravity lead to a calculated projection of the expected aroma profile and the color of the resulting beer The basis is the Malt-Aroma-Wheel, which was recently developed for a wide range of different malts. The projected beer profiles are compared with tasting results. This indicates the intensities of characteristic aroma components of the original malts and how much of those are found in the final beer. This tool is a big help for the development of new beer types and variation of existing beer styles.

Jens Voigt received a Dipl.-Eng. (M.S.) degree in brewing and beverage technology from TU München-Weihenstephan, Germany, in 1985. He started his career with A. Steinecker $\mathrm{GmbH}$, Freising, Germany, as a technical engineer in brewhouse, fermentation, and filtration equipment. He held sales, product, and management positions with Steinecker until 1995. From 1988 until 1992 he worked on his doctorate in brewing technology on beer foam from Weihenstephan (Prof. Narziß). In 1996 he joined Doemens Brewing School in Munich, Germany, as managing director. In late 1997 he joined Heinrich Huppmann GmbH, Kitzingen, Germany, as key account manager for brewery equipment and was managing director of brewmaxx, a supplier of software solutions for the brewing industry. From 2004 to 2012 he was a research associate with Prof. Karl Sommer (mechanical engineering and process technology) at WZW (Wissenschaftszentrum Weihenstephan [Center of Life Science, Technische Universität München-Weihenstephan]), working on brewing and beverage process technology issues. In 2012 he joined the University of Applied Sciences, Trier, as a professor in beverage technology. He is member of MBAA and IBD, a member of the editorial board in the Journal of the Institute of Brewing, and honorary associate professor of the University of Nottingham, U.K. 